\title{
EARTHEN SPACE - WORKSHOP AT THE FACULTY OF ARCHITECTURE, BRNO UNIVERSITY OF TECHNOLOGY
}

\author{
EVA NEUMAYEROVA, LENKA BAZIK
}

Brno University of Technology, Faculty of Architecture, Poříćí 5, 63900 Brno, Czech Republic Tutor: doc. Ing. Ivana Žabičková, CSc.

Theme of the dissertation: Economic and social limits of the use of earth in architecture. Role of education.

xaneumayerova@fa.vutbr.cz

\begin{abstract}
The Earthen Space workshop for students of FA BUT took place in the autumn of 2020 and included a review of the teaching concept for students of architecture's work with earth within the faculty project. This article describes the course and the content of the workshop, analyses the creation and teaching procedures from the perspective of the organisers and creators of the concept, and records the results of the project. It also assesses the potential of practical experience with earthen building material in the education of architects.
\end{abstract}

KEY WORDS: earthen building material, vocational education in architecture, earthen construction workshop

\section{Introduction}

The Earthen Space workshop was intended for 6-12 students and was divided into three days.

The partial goals of the project were:

- Introduction of future architects to earth as a contemporary sustainable material and show how it is suitable for modern construction

- Practical experience with earth 
- $\quad$ Creative team work

- Pilot training programme and data collection as part of the research of the authors of the paper:

- analysis of creative outputs from the workshop (Lenka Bazik)

- examination of the educational programme with earth as the building material (Eva Neumayerova)

\section{Intuitive design of students when working with earthen material - analysis of creative outputs - Lenka Bazik}

One of the points of the workshop was the students' own creative intuitive work with earth. After the theoretical part and practical tests of the material, students were given the following assignment: "Create any ideal space / shape that you consider most suitable for this particular building material. Use previous theoretical and practical knowledge of the material, and especially your own intuition. "

The students then formed their own small-scale earthen elements for ninety minutes. Some formed concrete elements that represented their initial association with earth, others formed without a primary idea of the result, that is, more intuitively. Elements created intuitively are further analysed as case studies.

\subsection{Case No.1}

The student prepared an earthen mixture and processed it with her hands until the mass was smooth enough. Subsequently, the student created finger dots in the finished form to ensure a smooth surface, without cracks. The round form of the element was thus created purely by the natural touch of the hands during processing (Fig. 1).

\subsection{Case No.2}

The student proceeded by trial and error, as she tested what the earth could do. As she could not create the desired shape purely from earth, she took other materials to help, such as wood and stone. The resulting organic form of the element arose only from the pleasure of working with earth without initial intentions (Fig. 2).

\subsection{Case No.3}

The student began to process the earthen mass with no idea of the result, but in the course of working with the material, the idea of space as a shelter arose. Thus, she created an inner space made of earth, both from the sides and from the top. In the next phase, 
she added earthen balls to the space, which were created by natural processing of the material in the palms (Fig. 3).

The above examples illustrate the work of young architects who encountered earth as a building material for the first time. The small constructions they produced have unambiguously round shapes created by the processing of earthen material in the palms. The earth is used for both vertical and horizontal structures, with the possible use of other materials. The thickness of the structures is ambiguous because the subsequent drying of the material was not taken into account.

\section{The educational programme "Earth in architecture" - methods and application in practice - Eva Neumayerova}

Within the workshop, the educational programme, based on the research performed within the author's dissertation was to be examined. The author analysed the success of the of the programme, as evaluated by the students, and the benefits of practical teaching with earth.

The three-day programme was attended by ten students from different years of study (6 students from the Bachelor's, 3 students from the Master's, and 1 student from the doctoral study programme).

The programme consisted of theoretical and practical parts. The theoretical part, prepared by the author of the paper, covered the morning programme of the first day of the workshop. The rest of the programme was filled by a practical workshop.

The following procedures were chosen:

\section{The theoretical part - lecture}

The introductory part of the lecture contained a basic overview of the historical development of the use of earthen building materials. It also focused on material characteristics, advantages and disadvantages, the possibility of combinations with other building materials, an overview of construction technologies and applications in structures, examples of successful implementations, recommended literature, and preparation for the practical part of the workshop containing the theoretical basis for evaluating suitable building earth.

\section{Practical part - Workshop}

The practical workshop, focused on craft skills and principles of implementation of earthen structures, was to show the importance of practice for understanding the behaviour of 
the material and consisted of the following parts:

- Understanding the knowledge of material behaviour - testing of the material mixture in practice and the principles of assessment of a suitable earthen mixture for construction purposes and its optimisation (Fig. 4.5)

- Earthen construction technologies in practice - creation of building elements from earth - with the example of manual production of earthen bricks and rammed earth (Fig. 6)

- Design and implementation of an earthen element - in this final part, students worked in two groups, with the task of creating a geometric shape, an architectural element from the material that was made available. The students in the first group tried to design and create a brick element from bricks with earthen mortar, the second group had material available for creating an element from rammed earth - an earthen bench and its decorative design. During the implementation, it was possible to try both technologies. (Fig. 7,8,9)

\subsection{Determining the success of the workshop based on the feedback of the participating students in the form of a questionnaire}

The feedback from students was to check the success and contribution of the teaching concept and to provide the basis for the possible optimisation of the programme as another possible use in the teaching of architecture students. Students were given a questionnaire prepared by the author, in which ten open questions were asked, four questions were to be completed before the workshop and six questions after the workshop.

Before the workshop, the questionnaire was used to find out:

1. Previous experience with a project or implementation of earth

2. Previous educational experience with earth as a building material

3. Reasons for participation in the workshop

4. Student expectations

After the workshop, the questionnaire was used to find out:

5. The degree to which students' expectations were met

6. The greatest benefit of the workshop perceived by students

7. Evaluation of the theoretical and practical parts

8. Recommendations for the course of the workshop resulting from the experience of students

9. Recommendation of the inclusion of earthen building materials in regular teaching at faculties of architecture.

10. Overall evaluation - the degree of strengthening students' awareness and interest in 
the application of earth in further practice

\section{Evaluation of students' answers in the questionnaire before the workshop:}

ad 1) The vast majority of interviewed students / workshop participants had not encountered a project or implementation where unfired earth was used.

ad 2) Students had so far encountered earth at the FA only to a limited extent, in teaching of the subject of building materials.

ad 3) Students mainly stated their interest in "feeling" the earth, working "with their hands", getting practical experience with earth, and their interest in understanding earthen structures and "natural building materials" in general.

ad 4) Students expected to get information about the principles of design of earthen structures and ways of appropriate use of earth in structures, and to gain theoretical and practical knowledge for the implementation of earthen structures.

Student's answer: "I want to learn how to work properly with earth so it lasts as long as possible. (To find out) what it allows and what it doesn't."

Student's answer: "I want to learn various techniques for working with earth, its properties, how to work with it in architecture and create your own work."

\section{Evaluation of students' answers from the questionnaire after the workshop:}

ad 5) The workshop met the expectations of students

ad 6) In terms of the benefits of the workshop, the possibility of practical work with the material, the involvement of external experts and the possibility of consultation with an external lecturer (expert from practice) was especially appreciated.

Student: "The benefit was definitely the "feeling" of the earth in various forms... In addition, I realised that the architect should know the material and find out the limits of the material and its suitability for use. And it's hard to get by anything other than practice. "

ad 7) In the theoretical part, students appreciated the general overview and the overall concept, for future use of the programme, they recommended linking the theory with practice and presenting the parts of the theory devoted to specific technologies along with limited practical tasks. In the practical part, students appreciated the possibility of working with their own hands, working in a team and understanding the material. Students would also welcome experience with the application of plasters.

ad 8) As a recommendation for possible future use of the teaching programme / workshop, students proposed optimising the time schedule of the workshop by concentrating the programme, dividing it into shorter individual stages and adding more earthen techniques. 
ad 9) Students recommended including teaching about earth material in the FA schedule, preferably in the form of a workshop or optional subject, which would be focused on theoretical lectures, and especially on the practice, which is generally lacking in teaching.

Student's answer: "Include in the FA schedule as an optional subject, for those who are more interested in the material. "

Student's answer: "The workshop is an ideal solution for education with this building material"... "if earth should be included in the teaching, a comprehensive programme of practical teaching of more building materials should be offered."

Student's answer: "What is missing - practice."

Student's answer: "(More) Theoretical (work) and 2 or 3 practical exercises."

ad10) In their answers, students confirmed that the workshop programme significantly contributed to increasing their awareness of unfired earth and increased their motivation for further study of the material and its possible implementations.

Student's answer: "Definitely contributed. I'm already thinking about what to build in my garden. And of course, even with the designs, I will be attracted to the earth. "

Student's answer: "Yes, but it will still require more experience and study. I became really interested in it. "

The workshop met the set goals of the project. Prior to attending the workshop, students had minimal knowledge of earth as a building material. As future architects, they especially appreciated the possibility of implementing a small earthen element based on their own designs, the involvement of their creative work in the implementation of the building, as well as teamwork and the possibility of consultation with experts from practice. Students suggested including a practical form of education with materials as a common part of teaching at faculties of architecture.

The example of this workshop shows the importance of practical teaching with building materials for students of faculties of architecture and students' interest in working with earth. 

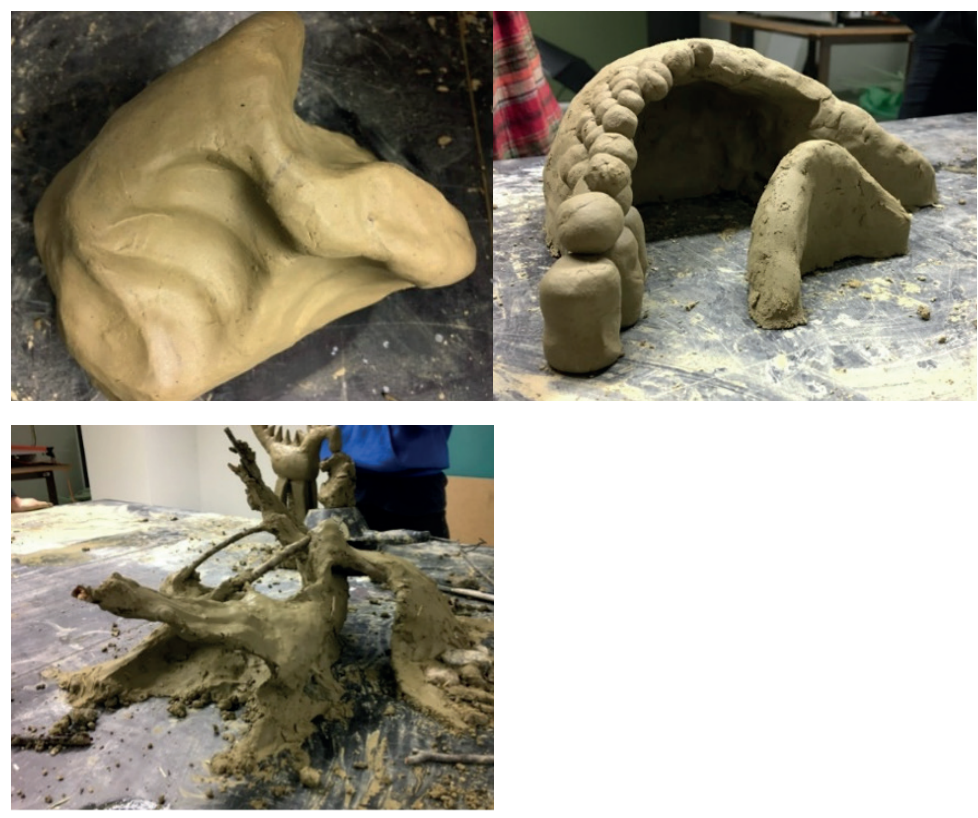

Fig. 1., 2., 3. Case No.1,2,3, photo: Lenka Bažík

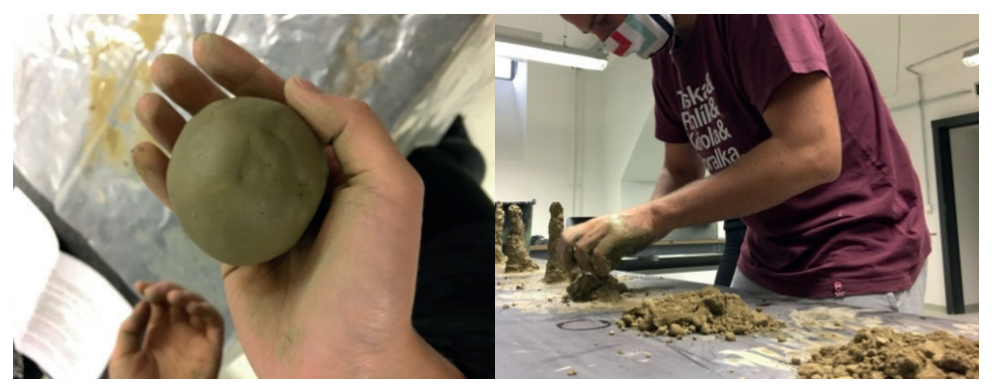

Fig. 4., 5. Tests of a suitable mixture, photo: Lenka Bažík

\section{Literature}

MINKE, Gernot, 2013. Building with Earth, Design and Technology of a Sustainable Architecture. 3. vyd. Basel: Birkhäuser Verlag GmbH. ISBN 978-3-0346-0822-0.

ŽABIČKOVÁ, Ivana, 2002. Hliněné stavby. Brno: Era.174p. ISBN 80-86517-21-7. 


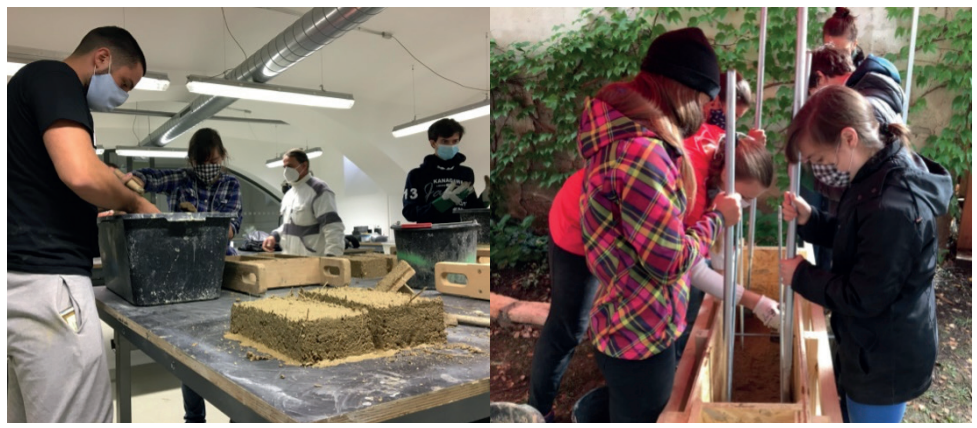

Fig. 6., 7. Hand-made earthen bricks and ramming into formwork, photo: Lenka Bažík

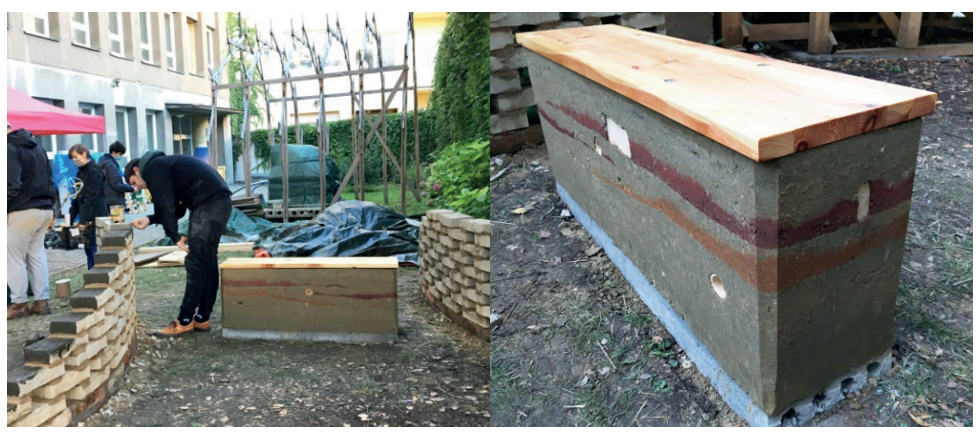

Fig. 8., 9. Creation of architectural elements from earth, photo: Lenka Bažík 